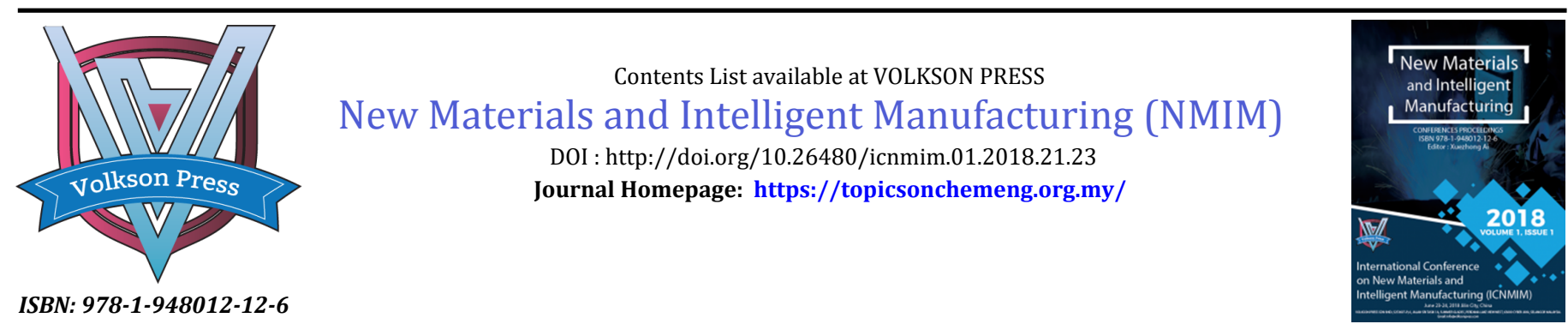

\title{
HYDROTHERMAL SYNTHESIS OF LITHIUM IRON PHOSPHATE CATHODES AND ITS ELECTROCHEMICAL PERFORMANCE
}

\author{
Liu Ling* \\ Institute of Petrochemical Engineering, Jilin Institute of Chemical Technology, No.45 Chengde Street, Jilin, China. \\ *Corresponding Author Email: lliuhit@163.com
}

This is an open access article distributed under the Creative Commons Attribution License, which permits unrestricted use, distribution, and reproduction in any medium, provided the original work is properly cited

\section{ARTICLE DETAILS}

\section{Article History:}

Received 26 June 2018 Accepted 2 July 2018

Available online 1 August 2018

\section{ABSTRACT}

$\mathrm{LiFePO}_{4}$ powders were prepared via hydrothermal synthesis. The effects of synthesis conditions on structure and electrochemical behavior of $\mathrm{LiFePO}_{4}$ were studied. The samples were characterized by X-ray Diffraction, Scanning Electron Microscope (SEM) and charge-discharge test. The study showed that $\mathrm{LiFePO}_{4}$ had an ordered layered structure and good electrochemical properties. The results showed that the performance of the powder was affected by the stoichiometric of the reactants and the synthesis parameters.

\section{KEYWORDS}

Hydrothermal synthesis, Lithium ion battery, Cathode material, Olivine $\mathrm{LiFePO}_{4}$

\section{INTRODUCTION}

Transition metal oxides, such as $\mathrm{LiCoO}_{2}, \mathrm{LiNiO}_{2}$ and spinel $\mathrm{LiMn}_{2} \mathrm{O}_{4}$ have been studied as cathode materials in lithium batteries. These materials have shown good cyclability and high capacity at high potential (around $4 \mathrm{~V}$ versus $\mathrm{Li} / \mathrm{Li}^{+}$). Spinel compounds, such as $\mathrm{LiMn}_{2} \mathrm{O}_{4}$, are promising candidates because of low toxicity and cost compared to $\mathrm{LiCoO}_{2}$ and $\mathrm{LiNiO}_{2}$, but they still have problems with Mn dissolution and they are low energy density. Recently, the phosphate $\mathrm{LiFePO}_{4}$ has been studied as the cathode-active material in Li batteries, because of it is expected low-cost, low toxicity and high theoretical specific capacity of $170 \mathrm{mAh} / \mathrm{g}$ [1-4].

$\mathrm{LiFePO}_{4}$ is one of the olivine formula $\mathrm{MNXO}_{4}$, where $\mathrm{M}$ and $\mathrm{N}$ are cations with different sizes. Its structure is composed of $\mathrm{PO}_{4}$ tetrahedra and $\mathrm{FeO}_{6}$ octahedra. Each $\mathrm{FeO}_{6}$ octahedron shares edge with one tetrahedron along $c$-axis and two corners in the $a b$-plane. This compound is environmentally benign and cheap, making it ideal for battery applications. A group researchers reported that $0.8 \mathrm{~mol}$ of lithium can be reversibly extracted at $0.05 \mathrm{~mA} / \mathrm{cm}^{2}$ [5]. The polyanion group stabilizes the structure and lowers the Fermi level of this redox couple through the Fe-O-X inductive effect, thus providing a higher voltage. Its discharge voltage is $3.5 \mathrm{~V}$, almost $0.7 \mathrm{~V}$ higher than $\mathrm{Li}_{3} \mathrm{Fe}_{2}\left(\mathrm{PO}_{4}\right)_{3}$. Since its formula has $1 \mathrm{~mol}$ of lithium, it should be charged first, and its theoretical capacity is $170 \mathrm{mAh} / \mathrm{g}$. During the recharge, its volume shrinks only about 6.8\%, comparable to that of $\mathrm{LiTiS}_{2}$, thus minimizing mechanical decrepitation and the resulting loss of electrical contact during cycling.

In all of these studies, $\mathrm{LiFePO}_{4}$ was synthesized by a solid-state reaction using electric furnaces, which require a lengthy firing at $300 \sim 800^{\circ} \mathrm{C}[6,7]$. Besides, the solid-state reaction needs $\mathrm{N}_{2}$ or Ar, which increase the cost of reaction. Comparatively the hydrothermal synthesis cost less, so it is worth to be investigated. In this paper, we exploited the advantages of hydrothermal synthesis, quick easy synthesis at low energy cost and readily scalable. We report the rapid formation of $\mathrm{LiFePO}_{4}$, where no impurities were observed, making it an excellent alternative to hightemperature synthesis. This method involves reaction at low temperature $\left(100 \sim 20^{\circ} \mathrm{C}\right)$ for a short period $(3 \mathrm{~h}$ to $10 \mathrm{~h})$, which is very good for commercialization of these compounds.

\section{EXPERIMENT}

\subsection{Synthesis procedure}

$\mathrm{LiFePO}_{4}$ was prepared by direct hydrothermal synthesis of $\mathrm{FeSO}_{4}, \mathrm{H}_{3} \mathrm{PO}_{4}$ and $\mathrm{LiOH}$ in the stoichiometric ratio 1.0:1.0:3.0. $\mathrm{FeSO}_{4}$ and $\mathrm{H}_{3} \mathrm{PO}_{4}$ solution were mixed first to avoid $\mathrm{Fe}(\mathrm{OH})_{2}$, because it is easily oxidized to $\mathrm{Fe}(\mathrm{III})$, then $\mathrm{LiOH}$ solution was added to the mixture with stirring for $1 \mathrm{~min} . \mathrm{pH}$ was 7.56 and the solution was quickly transferred to reactor for up to $5 \mathrm{~h}$ at $120^{\circ} \mathrm{C}$. After the sample was cooled, the $\mathrm{pH}$ was 6.91 . The light green precipitate was filtered and air-dried at $40^{\circ} \mathrm{C}$ for $2 \mathrm{~h}$. For several similar syntheses, pH was slightly different, and it had no effect on the final product. Several attempts had been tried with $\mathrm{Fe}(\mathrm{II})$ salt and $\mathrm{Li}_{3} \mathrm{PO}_{4}$, all of them had some impurities. When $\mathrm{FeCl}_{2}$ and $\left(\mathrm{NH}_{4}\right)_{2} \mathrm{Fe}\left(\mathrm{SO}_{4}\right)_{2}$ were used instead of $\mathrm{FeSO}_{4}$, the same compound was synthesized reddish impurities will be produced, especially when the iron salt is not new, but they can be easily separated from $\mathrm{LiFePO}_{4}$ in a centrifuge.

\subsection{Sructural and morphological characterization}

Phase characterization was done by powder X-ray diffraction technique on a Philips $1830 \mathrm{X}$-ray diffractometer using Ni filtered $\mathrm{Cu} \mathrm{K} \alpha$ radiation $(\mathrm{k}=$ $1.5406 \mathrm{~A}$ ) in the $2 \theta$ range of $10 \sim 100^{\circ}$ at scan rate of $0.1^{\circ} / \mathrm{s}$. Surface morphology of the particles was examined through SEM images obtained from Jeol S-3000 H Scanning Electron microscope and the chargedischarge studies were carried out using BTS-5V/3mA charge-discharge cycle life tester.

\section{RESULTS AND DISCUSSION}

\subsection{SEM analysis of $\mathrm{LiFePO}_{4}$ by different synthesis routes}

The synthesis routes of $\mathrm{LiFePO}_{4}$ can be classified into two kinds according as the reaction medium, they are solid-state reaction and hydrothermal synthesis. The solid-state reaction needs a higher temperature and requires inert gases. Moreover, the diameter of the powder is much larger. In order to minish the granularity of the productions, and decrease the impurities at the same time, the research always used liquid method to synthesize the powder, such as sol-gel method and hydrothermal 
synthesis. We used both solid-state reaction and hydrothermal synthesis to compose $\mathrm{LiFePO}_{4}$. The SEM images of $\mathrm{LiFePO}_{4}$ by these two methods are as Figure 1.

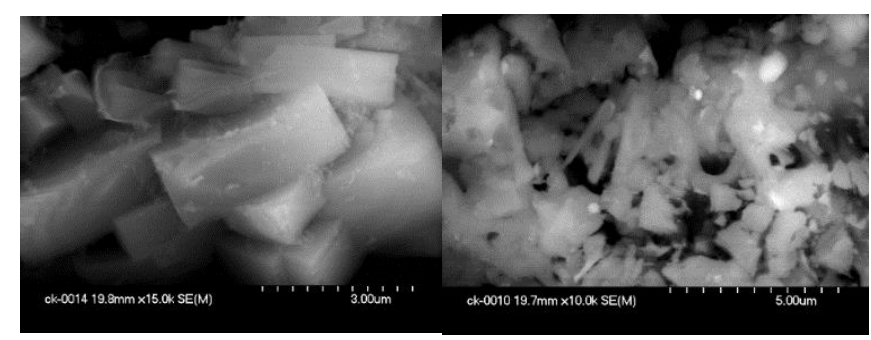

(a)

(b)

Figure 1: The $\mathrm{SEM}_{\text {of }} \mathrm{LiFePO}_{4}$ synthesized by different synthesis routes (a) hydrothermal (b) solid state reaction

The particle size of the $\mathrm{LiFePO}_{4}$ which was synthesized by hydrothermal route is homogeneous and small, the average particle size is about $3 \mu \mathrm{m}$, and this is smaller than the $20 \mu \mathrm{m}$ average size of $\mathrm{LiFePO}_{4}$ produced by solid-state reaction.

\subsection{Electrochemical performance of $\mathrm{LiFePO}_{4}$ with different $\mathrm{Li}: \mathrm{Fe}$}

The reactant proportion usually decides the product's final stoichiometric, chooses the suitable Li:Fe may suppress the mixed production, and obtains pure olivine $\mathrm{LiFePO}_{4}$. The experiment synthesizes $\mathrm{LiFePO}_{4}$ under the different Li:Fe reactant proportion. Figure 2. are the discharge curves and cycling performance of the product obtained under different reactant proportion at $0.1 \mathrm{C}$ discharge rate. when the $\mathrm{Li}$ :Fe ratio is $1.5: 1$, the discharge capacity is $44.26 \mathrm{mAh} / \mathrm{g}^{-1}$, the platform is not obvious, this is due to the impurity $\mathrm{FePO}_{4}$, its existence causes the product capacity greatly to reduce. Along with the $\mathrm{Li}$ content increase, the platform elevates and changes slow. When the Li:Fe is $3: 1$, the discharge capacity is $77.23 \mathrm{mAh} / \mathrm{g}$ 1. Although this four kinds of products have good cycling performance, but when Li content is lower, the first ten discharge capacities will rise.

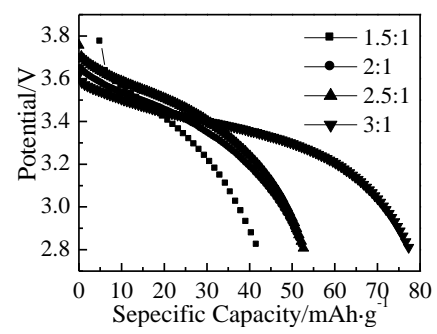

(a)

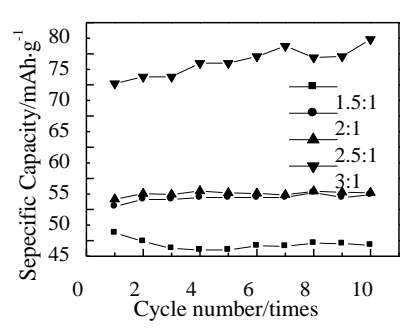

(b)
Figure 2: The 10th discharge curve (a) and cycling performance (b) for $\mathrm{LiFePO}_{4}$ with different $\mathrm{Li}: \mathrm{Fe}$

\subsection{Electrochemical performance of $\mathrm{LiFePO}_{4}$ by different synthesis parameters}

When the $\mathrm{pH}$ value is a constant $(\mathrm{pH}=8 \pm 0.05)$, the reaction temperature has the certain influence to the electrochemistry performance of the $\mathrm{LiFePO}_{4}$. The experiment carries in the different reaction temperature $\left(110^{\circ} \mathrm{C}, 120^{\circ} \mathrm{C}, 130^{\circ} \mathrm{C}\right)$. The discharging curve and cycling performance are shown in the Figure 3.

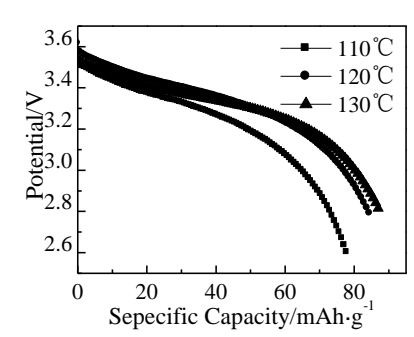

(a)

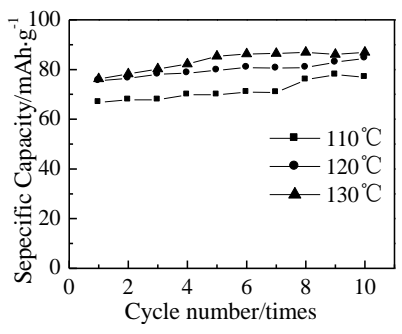

(b)
Figure 3: The10th discharge curve(a) and cycling performance(b)for $\mathrm{LiFePO} 4$ with different reactive temperature
The result of Figure 3. indicates that products obtained under $120^{\circ} \mathrm{C}$ and $130^{\circ} \mathrm{C}$ have similar discharging curves, but the discharge capacity and the platform of products obtained under $110^{\circ} \mathrm{C}$ are lower. Under three kinds of reaction temperatures the first ten discharge capacities all have the certain enhancement.

The reaction time also has a tremendous influence on the structure and electrochemistry performance of the powder. The reaction time is $5 \mathrm{~h}$ $6 \mathrm{~h} 10 \mathrm{~h} 、 24 \mathrm{~h}$, and the discharging curve and cycling performance of the powders obtained under different reaction time are shown in Figure 4. Along with reaction time lengthen, the voltage platform elevates, the discharge capacity increase. All of these show that the inside impedance has reduced, and the crystal lattice distortion are less. Along with the cycle time increase, the discharge capacity slightly rises.

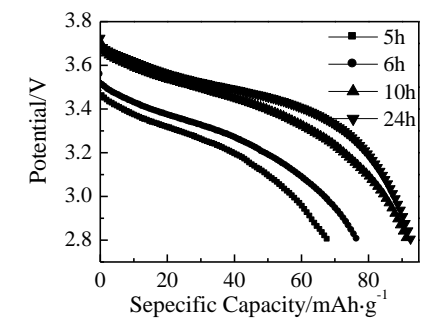

(a)

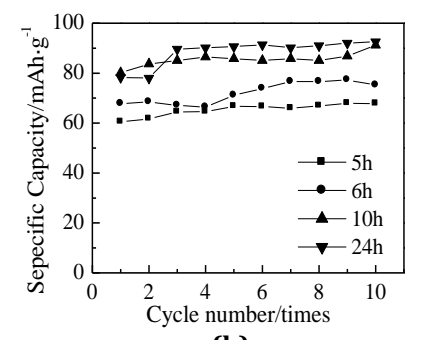

(b)
Figure 4:The 10th discharge curvea) and cyclingperformance(b) for $\mathrm{LiFePO}_{4}$ with different reactive time

The choice of drying time influences the crystal process, as well as the electrochemistry performance. The experiment operates under the same drying temperature; the products obtained by different dry time are analyzed as Figure 5.

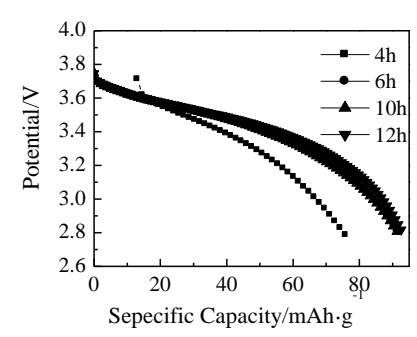

(a)

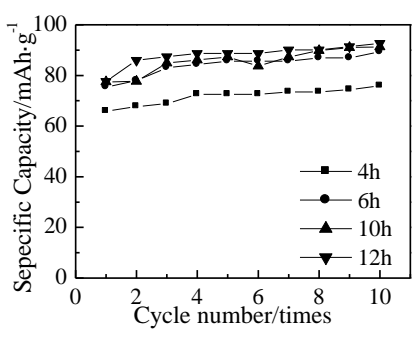

(b)
Figure 5: The 10th dischargecurve (a) and cycling performance(b) for $\mathrm{LiFePO}_{4}$ with different evaporation hours

We may see from the Figure 5, when the drying time surpasses $6 \mathrm{~h}$, the discharging curves nearly superpose. The $10^{\text {th }}$ discharge capacity is all about $91 \mathrm{mAh} / \mathrm{g}^{-1}$. Through the contrast of the discharging curves and cycling performance of products which obtained by different drying time, may discover the product which has a longer drying time has a good charge-discharge performance. As the drying time prolong, the discharge capacity of the battery has risen, as well as the discharge platform. After the drying time surpasses $6 \mathrm{~h}$, the tendency is not obvious.

\section{CONCLUSIONS}

Studied the synthesis condition of $\mathrm{LiFePO}_{4}$, the optimized conditions are as follow: the reactant mole ratio is $\mathrm{FeSO}_{4}: \mathrm{H}_{3} \mathrm{PO}_{4}: \mathrm{LiOH}=1: 1: 3$; the reaction temperature is $120^{\circ} \mathrm{C}$, the reaction time is $10 \mathrm{~h}$, in inert gas dry $6 h$.

\section{ACKNOWLEDGMENTS}

This project was supported by the Science and Technology Research Project in Jilin Institute of Chemical Technology under Contract No.2018073.

\section{ABOUT THE AUTHORS}

Liu Ling (1980-), female, Ph.D., associate professor. Mainly engaged in the research of lithium ion battery materials. Email: lliuhit@163.com 


\section{REFERENCES}

[1] Prosini, P.P., Zane, D., Pasqualim. 2001. Improved Electrochemical Performance of $\mathrm{LiFePO}_{4}$-Based Composite Cathode. Electrochimica Acta, 46, 3517-3523.

[2] Striebel, K., Shim, J., Srinivasan, V. 2005. Comparison of $\mathrm{LiFePO}_{4}$ from Different Sources. Journal of The Electrochemical Society, 152 (4), 664670.

[3] Takahash, M.i., Ohtsuka, H., Akuto, K. 2005. Confirmation of Long-term Cyclability and High Thermal Stability of $\mathrm{LiFePO}_{4}$ in Prismatic Lithium-ion Cells [J]. Journal of The Electrochemical Society, 152 (5), 899-904.

[4] Sylvain, F., Frederic, L.C., Carole, B. 2003. Comparison Between Different $\mathrm{LiFePO}_{4}$ Synthesis Routes and Their Influence on its Physicochemical Properties [J]. Journal of Power Sources, 119-121, 252-257.

[5] Padihi, A.K., Nanjundaswamy, K.S., Goodenough, J.B. 1997. Phosphoolivines as Positive Electrode Materials for Rechageable Lithium Batteries. Journal of The Electrochemical Society, 144 (4), 1188-1194.

[6] Delacourt, C., Laffont, L., Bouchet, R. 2005. Toward Understanding of Electrical Limitations (electronic, ionic) in LiMP04 $(\mathrm{M}=\mathrm{Fe}, \mathrm{Mn})$ Electrode Materials. Journal of The Electrochemical Society, 152 (5), 913-921.

[7] Chung, S.Y., Blocking, J.T., Chiang, Y.M. 2002. Electronically Conductive Phospho-olivines as Lithium Storage Electrodes. Nature Materials, 2, 123128. 